\title{
A BRIEF REVIEW ABOUT FLOATING OFFSHORE WIND TURBINES PROJECTS
}

\author{
Aurel - Dan Maimon \\ University "Dunarea de Jos" of Galati, \\ Faculty of Naval Architecture, Galati, \\ Domneasca Street, No. 47, 800008, Romania, \\ E-mail:dan.maimon@ugal.ro
}

\begin{abstract}
The main purpose of this article is to point out the actual progress on offshore wind turbine projects by stressing their differences of construction in all their main parts: turbines, floats, mooring and foundations systems and the installation characteristics. Floating offshore wind turbines offer great savings in terms of installation: the float-turbine assembly can be done in basin or dock, regardless of weather conditions, the towing to the site is done by simple offshore tugs, the anchorage of the wind turbine requires the help of anchor hoisting vessels, very common in the offshore oil and the anchorage is done quickly by comparison to the installation of a conventional offshore wind turbine that requires many specialized vessels, type heavy haulage carrier for foundations and jack-up vessels for the installation of the turbine.
\end{abstract}

Keywords: wind turbines, floating platforms, anchoring lines

\section{INTRODUCTION}

From the moment COP21 agreement in Paris has just been signed, aiming to contain global warming under the $2^{\circ} \mathrm{C}$ threshold by 2100 , it is useful to focus on marine renewable energy, which is undeniably one of the best alternatives to fossil fuels. Among these energies of the future, currently stands out a category that is on the rise, wind power floating offshore. In the tradition of onshore wind and offshore wind, it represents the latest technological advance in this area.

The onshore wind, the most mature wind turbine technology, is very often criticized because of the visual and noise pollution it causes. Areas favorable to its development are limited and strict urban regulations hamper the creation of new projects. Offshore wind power poses a solution to these problems. However, the installation of these wind turbines is limited to depths of up to 40 me- ters, because beyond that, the costs of installation and the technical constraints are problematic. It becomes difficult and above all very expensive to realize the foundations of the wind turbine in the sea floor. The floating wind allows to get rid of this depth limit. It is currently estimated that a wind farm can be built in areas where bathymetry reaches 300 meters.

At sea, in the absence of relief, the wind flows in a laminar manner, which increases the yield of offshore wind compared to land. Moving further away from the coast with the floating one allows to reduce even more the influence of the reliefs on the flow of the wind. The float then gives the possibility of reaching extremely interesting, stronger and more regular wind farms, and thus increases its load factor. By way of comparison, the average annual load factor of the onshore wind energy was $21.7 \%$ in 2011 . Offshore wind energy was $41.1 \%$ on average in 2015 . 
Exploiting deep-sea deposits is not the only benefit of floating. The total cost of installation of a conventional offshore wind turbine varies greatly from one wind field to another, on average it is estimated that it is between 2 and 4 million euros per installed MW. On this point, floating offshore wind turbines offer great savings. The distance between the assembly site and the installation site is going to be a determining factor of the price, but the total cost will remain much lower than that of the posed one.

Since the assembly is easily towable, major repairs to a floating wind turbine can be done at the dock. In the shelter, maintenance is no longer dependent on weather conditions, no longer requires the help of expensive ships and handling of heavy parts is easier.

\section{WIND TURBINES}

\subsection{DIFFERENT CATEGORIES OF WIND TURBINES}

Whether on land or at sea, only two large categories of industrial wind turbines stand out. The difference is done by the axis of their rotor that can be either horizontal or vertical. Currently horizontal axis wind turbines make up almost all onshore and offshore wind farms around the world, including because their performance is superior. However, the axis wind turbines vertical features have characteristics that interest more and more engineers, especially when it comes to park design floating offshore.

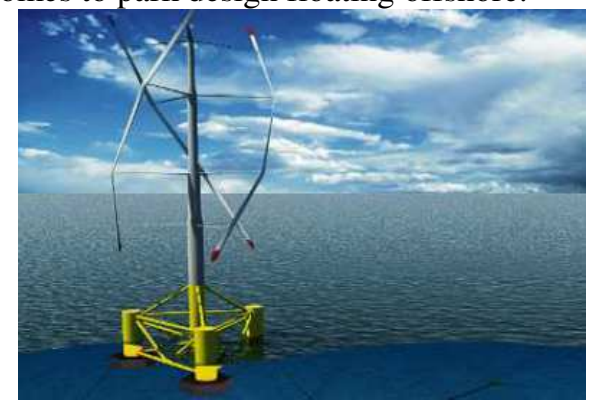

Fig.1. Wind turbine with vertical axis of Nénuphar
There are several subcategories of horizontal axis wind turbines on the market. Some are "upwind" when designed to operate in the direction of the wind and others "downwind" when the rotor is placed downstream of the mast by relation to the direction of the wind.

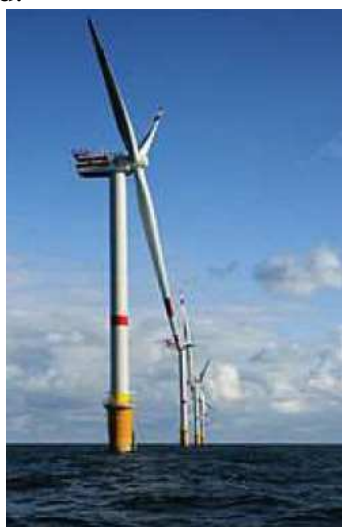

Fig.2. Wind turbine with horizontal axis of the Thornton Bank wind farm, Belgium

Wind turbines can be variable speed or constant speed. We talk about variable speed when speed of rotation of the rotor varies according to the speed of the wind. In contrast, a wind turbine runs at constant speed when the rotational speed of the rotor remains constant regardless of the wind speed.

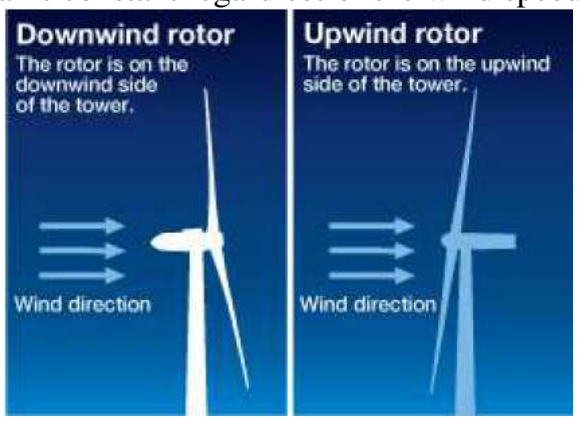

Fig.3. Wind turbines with upwind and downwind rotors

The transmission between the axis and the generator can also differ according to the models. If the generator is an engine asynchronous for example a multiplier is coupled on the rotor. This allows to increase the 
speed of rotation and to reach the operating ranges of the generator, around 2000 RPM. On the other hand, this increases the risk of failure and requires additional maintenance. In the case of engine synchronous permanent magnets, the multiplier is not necessarily useful, the wind turbine is said to direct drive. In addition to saving weight and reducing the number of rotating parts, the direct drive offers a better efficiency of the turbine. However, this requires the use of a frequency converter to keep a constant frequency of the current produced despite the variable speed of the rotor.

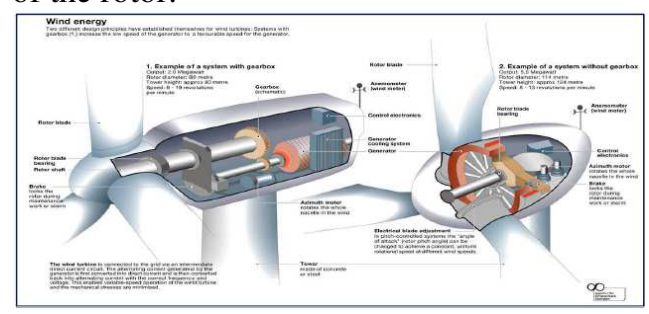

Fig.4. "Multiplier" on the left and "Direct drive" on the right

For offshore floating wind turbines currently used are offshore wind turbines classic, they have no specificity to floating. This allows you to use a technology already mature, with successful production and logistics chains. It is a safe bet that in the future, floating-specific wind turbines will still appear. For example, these could be lightened, with less steel and more composite materials, which would reduce the size of the float. We could also consider wind turbines whose equipment at the masthead would better support the acceleration due to roll and pitch. We can still imagine a rotor on cylinders, which would be stabilized by gyroscope, to keep the blades in the best axis relative to the wind, despite the movements of the float.

\subsection{HORIZONTAL AXIS WIND TURBINE}

The architecture of a horizontal axis wind turbine includes the following elements:
- The tower, it supports the nacelle and allows to raise the height of the rotor. The interest is to capture higher winds, therefore more regular and stronger. This one consists of 4 to 5 steel sections for the most powerful wind turbines. It can measure up to 90 meters for a wind turbine of $8 \mathrm{MW}$. At its base are all the technical elements necessary for the transformation of the voltage produced and the connection to the network.

- The nacelle, located at the top of the tower, houses the essential components of energy production electric. It can include the alternator and its coupling, the system of alternator cooling and the engine used to orient the nacelle according to the wind direction.

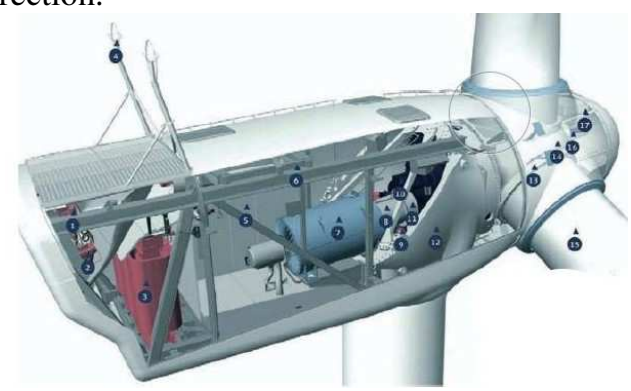

Fig.5. Descriptive diagram of a wind turbine nacelle

- The rotor, it is composed of the hub and the blades. Its diameter reaches 180 meters, with blades 88 meters, for the most powerful wind turbines. The materials currently used for these the latest are fiberglass and carbon fiber. Their profile is modeled according to the power of the turbine and the rotational speed of the rotor. A system of cylinders integrated into the hub allows to vary the angle of attack of the blades according to the speed of the wind. In case of storm it is possible to change the angle of attack so as to obtain a zero-engine torque and therefore protect the wind turbine. All the large wind turbines have 3 blades. Indeed, this choice proves to be the best compromise between the efficiency of the wind turbine and its cost of manufacturing. 
For an $8 \mathrm{MW}$ wind turbine, the total height reaches 210 meters at the end of the blade, for a total weight more than 500 tones.

\subsection{VERTICAL AXIS WIND TURBINE}

There are 2 large families of vertical axis wind turbines, those of type Savonius and others of Darrieus types. Only wind turbines Darrieus are suitable for high powers; indeed the Savonius type performance collapses as one increases dimensions because of its high mass. However, they possess all the same characteristic that defines them, their rotor revolves around a fixed vertical tower, called a finned stator. Vertical axis wind turbines have the same technical elements as those with horizontal axis only their layout differs, almost all the elements are located at the foot of the tower.

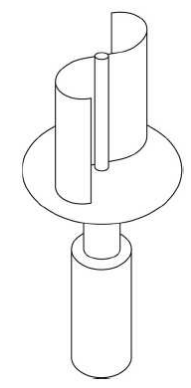

Figure 6. Savonius type vertical axis

Among the Darrieus type wind turbines, there are 3 categories, the cylindrical, the $\mathrm{H}$ and the helical. The last have the best performance, but the complex form of their blades makes them more expensive.

The advantages of the vertical axis wind turbine are numerous, especially in the field of floating offshore wind. It can work especially regardless of the direction of the wind, unlike the wind turbine axis horizontal which must direct its rotor in the axis of the wind to function. But his main asset remains its center of gravity. Indeed, the vertical axis wind turbine concentrates most of its mass at the foot of the mast, where all the essential components for the production of energy are located electric. The consequence is a consid- erable lowering of the center of gravity in comparison with a wind turbine with a horizontal axis, where most of its mass is at the top of the mast. The benefit of having a low center of gravity is of course able to reduce the size of the float that supports it. Get then follows a financial gain over the entire production chain, until installation. In addition, maintenance is facilitated by the arrangement of the elements at the foot of the mast, no need to climb into a gondola almost 100 meters high.

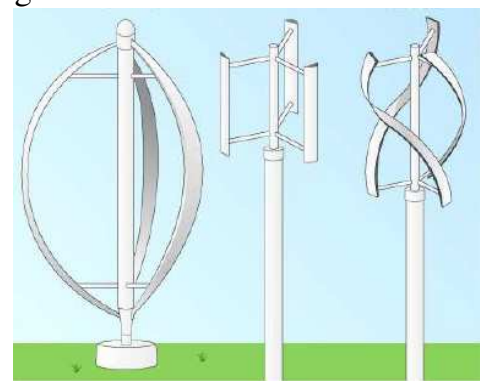

Figure 7. Darrieus type vertical axis

On the other hand, vertical axis wind turbines have a lower efficiency than wind turbines horizontal and does not start automatically, it will be necessary to use the generator in motor mode for start the rotation movement. In addition, the manufacture of blades is difficult because of their great cut. Another disadvantage has been noted, it is about the variations of torque which applies on the blades during rotation. When the blade is in the wind, it undergoes a strong pressure, then, when it comes under the pale wind it a sudden depression occurs. This causes fatigue at the axis which can result in more regular maintenance.

\section{THE FLOATS}

Currently we can inventory about sixty offshore wind projects with a size of $30 \mathrm{MW}$ or larger floating around the world. Some are just a reflection, when others are already at the pilot project stage. Among this set three main categories of floats are distinguished: the semi-submersible float, the Tensioned Leg Platform and the buoy SPAR. 


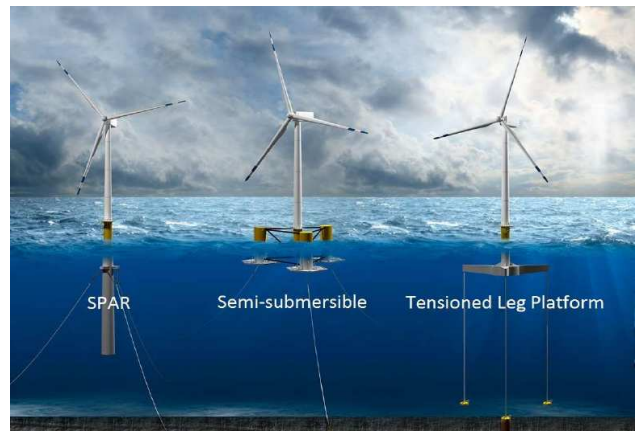

Figure 8. Three types of floats

\subsection{SEMI-SUBMERSIBLE}

This is certainly the most common type of float among all existing projects. It is inspired by what is already being done in the oil and gas offshore. As a result, even if the structure optimized for wind, this type of technology has already been well mastered for many years. Current projects are almost all in the form of a tripod. The structure of the float has an immersed part and its anchor lines, which are not tight, need only resist the drift of the whole. To ensure good stability, the float often requires a large structure and therefore heavy, around 2000 tons before ballasting, but in return its draft remains reduced, around 10 meters. This low draft makes it possible to envisage a float-turbine assembly at the dock. Moreover, it can be easily manipulated, whether for installation or towing, only AHTS6 type vessels or deepsea tugs are required. Made of steel, concrete, or a combination of both, its design cost remains reduced despite the relative complexity of its forms. Moreover, this type of float being in regularly produced for offshore oil, this technology requires little Research. Its anchorage will however have to be robust because of its large tonnage and therefore more expensive. The need for an automatic ballast system also comes increase the price of the semi-submersible float. Indeed, to limit the taking of shelter when the wind change direction and keep the whole flat, it moves a certain amount of ballast water between the volumes of the structure.

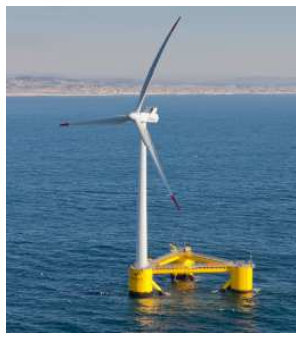

Fig.9. WindFloat by Principle Power

WindFloat is currently one of the most advanced in the field of floating wind. In 2011, the American company Principle Power has launched in 3 Miles off Aguçadoura in Portugal, a $2 \mathrm{MW}$ horizontal axis turbine on a float semi-submersible. Its displacement is 5500 tons. This one is composed only of steel, retained by 3 lines of catenary moorings and takes the shape of a tripod, the turbine then resting on one of the feet. Assembled in Lisbon, the wind turbine has been towed over 200 Miles to its installation site. In 2014, it produced already more than 11 GWh, with a load factor greater than $47 \%$. She also suffered storms with waves up to 9 meters. Thus, the feedback from the demonstrator allowed to validate the concept and to imagine a better optimization of the whole, in particular a reduction in the size of the float and an increase in the power of the turbine. Deployment pre-commercial should come into being in 2018, with 3 or 4 wind turbines for a total power of $25 \mathrm{MW}$. The concept also tends to be exported to the United States and Scotland, where Principle Power has presented park projects on a commercial scale.

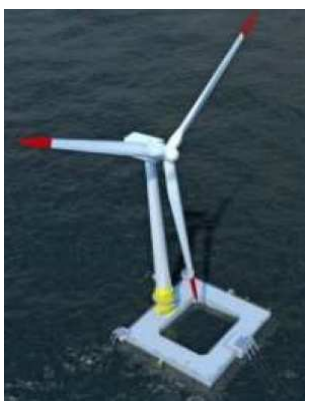

Figure 10. Damping Pool by Ideol 
Ideol, a French company, offers a semisubmersible float innovative, the Damping Pool. This one owns a central opening, where water can rush, which significantly improves the stability of the whole. Indeed, the volume of water contained in the center of the float is come up against the movements of the wind turbine caused by the swell and thus dampen the oscillations of the wind turbine. The Damping Pool concept offers the benefit of being compatible with all the wind turbines on the market, whatever their power. Its dimensions remain compact, 35 to 50 meters side for a wind turbine of 2 to $8 \mathrm{MW}$. His draft is around from 7 to 8 meters, which allows easy handling in most port facilities. Ideol recommend a concrete construction but also offers a steel solution, for where it would be cheaper and more accessible than concrete. Ideol is positioned currently on the Floatgen project off Le Croisic where he should deploy a demonstrator 2016. The Damping Pool should also be exported to Japan, where the installation of two demonstrators is planned for 2016-2017 and in Taiwan waters, where Preliminaries have recently been signed.

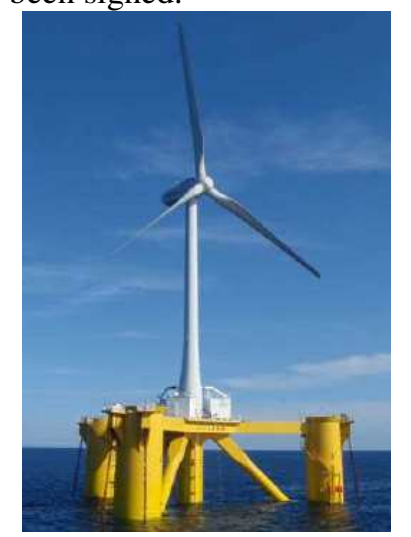

Figure 11. Fukushima Mirai by Mitsui Engineering \& Shipbuilding

Since the disaster of Fukushima in 2011, Japan has begun an energy transition tour towards marine renewable energies. The country was particularly interested in wind energy floating offshore, to become today a precursor in the field. From 2012 on Japanese government, with the support of a consortium of industrialists, decided to develop a pilot farm at 10 Miles off Fukushima, this is the Fukushima Forward project.

The first phase of the Fukushima Forward project begins so in 2013, when Mitsui Engineering \& Shipbuilding installs on the site, Fukushima Mirai, a turbine with axis 2 MW horizontal on a semi-submersible float of 2500 tons of steel. This one consists of three columns that can be ballasted to ensure stability of the whole and the turbine rests on a fourth central column. Its draft reaches 16 meters, which allows it to be installed in funds starting at 50 meters.

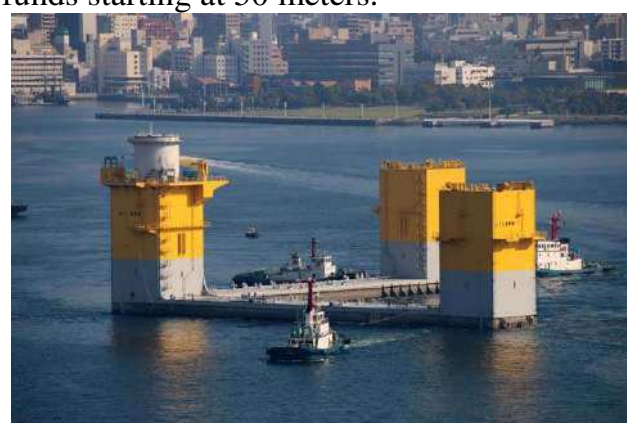

Figure 12. Fukushima Shimpuu by Mitsui Engineering \& Shipbuilding

In September 2015, the second phase continues with the construction of the most powerful offshore wind turbine in the world, Fukushima Shimpuu by Mitsubishi Heavy Industries. Its $7 \mathrm{MW}$ horizontal axis turbine rests on one of the 3 columns of a float in Vshaped and had to start his test period midDecember 2015. Its width reaches 90 meters and its final draft would be around 30 meters.

\subsection{SPAR (Single Point Anchor Res- ervoir)}

The deepest oil platform in the world, Perdido in the Gulf of Mexico, is built on a SPAR float anchored at 2.438 meters deep. Indeed, this type of float is intended especially at great depths. Immersed in the extension of the turbine, its cylindrical shape and its heavy ballast considerably lowers the center 
of gravity of the whole. This him provides great stability, with as response to the swell of the movements large but very slow, which avoids too much accelerations at the masthead of the turbine. This technology float does not require any automatic ballast system, with the advantage of the cost of the float. However this stability is obtained at the expense of a strong draft, between 70 and 82 meters for a $6 \mathrm{MW}$ turbine. The SPAR float is therefore limited to depths beyond 100 meters. Its handling is also more complicated than the semi-submersible and the TLP8. In Indeed, the docking assembly of the turbine and its float is not possible, it then proceeds as follows: the float is towed horizontally and without its ballast, to the wide. He is joined by a jack-up type ship to be rocked vertically and ballasted to receive the turbine. of the heavy haulage carriers then bring the mast, the gondola and the blades that are added in turn to the float, as it sinks progressively under the surface of the water. The finally assembled wind turbine will finally be towed to its installation site. Because of these same reasons, major repairs can not be made at the dock, ships will have to be to intervene directly on the wind farm, as would be done in offshore wind turbines posed. To remedy this problem, companies like the Japanese Modec or the Norwegian Ulstein have imagined for Statoil a removable fixing system to separate the float and the turbine easier. The cylindrical shape of the SPAR float does not represent a major technical challenge to the realization, it offers the advantage of being easy to design, thus lowering the cost to construction.

The Hywind concept of the Norwegian Statoil is currently the offshore wind project the most mature floating in the world. The demonstrator is deployed since 2009 off Stavanger in Norway, which makes him the first prototype floating wind turbine functional in the world. Its turbine axis horizontal develops a power rated $2.3 \mathrm{MW}$, its float is retained by 3 catenary lines and its draft reaches 100 meters.

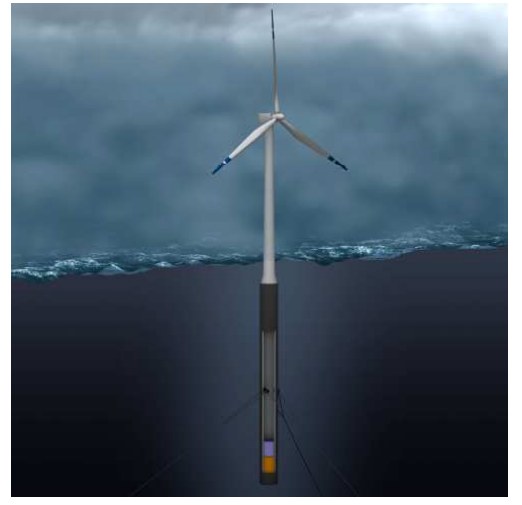

Fig.13. HyWind by Statoil

Hywind has already provided the network with more $32.5 \mathrm{GWh}$ since the beginning of its operation in 2010, with an excellent load factor, around $50 \%$. Statoil's Hywind program has cost 400 million Norwegian kroner, from conception to deployment in the waters Norwegian. This great feedback has already allowed Statoil to improve its prototype and to export its concept to the market. Indeed, the Norwegian industrialist has been selected to deploy in 2017 a pilot wind farm in North East Scotland, consisting of 5 wind turbines of $6 \mathrm{MW}$ per unit, wet between 95 and 120 meters deep. The diameter of their rotor reaches 154 meters and their maximum height is 181 meters at the end of the blade.11 In addition to having increased the unit power of the turbine, Statoil reduced the draft of the float between 70 and 82 meters, increasing the diameter of the cylinder and increasing its ballast. The latter reaches a total of 8,000 tonnes with ballast, a part will be filled with water and another with high density concrete. The percentage distributed between the two is currently under study by Statoil. These modifications increase the Hywind's competitiveness in the market, with a reduction in material costs and an installation possible in slightly shallower areas. Statoil announces that its future pilot farm in Scotland will be able to power the electricity consumption of 20,000 homes. 


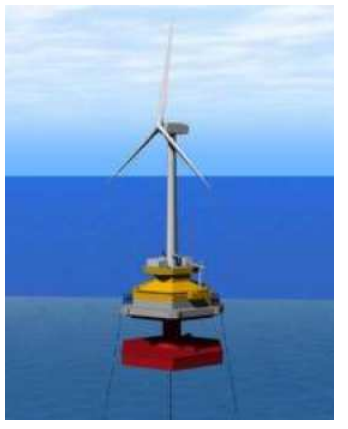

Figure 14. Fukushima Hamakaze by Japan Marine United

Still in the framework of the Fukushima project Forward, a third wind turbine, Fukushima Hamakaze, should be installed in 2016. Its $5 \mathrm{MW}$ turbine is produced by Hitachi and will be placed on a SPAR float, designed by Japan Marine United and currently in construction in Sakai, near Osaka. Called Advanced SPAR, the last improves a SPAR classic by adding a weighted sub platform at the foot of the float. The interest of this additional structure is twofold. When the wind turbine pitched or rolls, the hydrodynamic pressure exerted on the sub-platform will come to oppose each movement and thus dampen it. The second advantage is to be able to reduce the draft of the float to ensure easier handling and adapt it to smaller funds. On the other hand, design becomes more complex compared to a conventional SPAR buoy and increases its cost. In the long term, the Fukushima Forward project will select the best-performing float for the construction of the wind farm on a commercial scale. The choice will therefore be between the two semisubmersible floats and Advanced SPAR. The Japanese government hopes to enlarge the park until a total power of $100 \mathrm{MW}$, for the Olympic Games it will organize in Tokyo in 2020 .

\subsection{TLP (Tensioned Leg Platform)}

At present, unlike semi-submersible and SPAR, no wind turbine demonstrator with TLP float has been built in the world. However, this technology has already proven it- self in the field of offshore drilling platforms and has excellent stability qualities. Unlike the semi-submersible, most of the TLP float is kept submerged by a tensioned anchor pulling it to the bottom. Mooring lines, subjected to an effort important, must withstand drift and buoyancy buoyancy. In return, this excess buoyancy retained by taut lines provides great stability to the whole. Compared to the semi-submersible float, the tonnage of the structure of a TLP float is almost divided by two. This results in a lower construction cost, as well as easier handling during towing and installation. Switching on the anchor lines, however, requires the assistance of specialized vessels and sometimes the presence of winches on the float to adjust the tension. The TLP then widens the cost gap with its shorter mooring lines than the catenary anchorage, because the price of anchorage represents a significant part of the price of the whole. Furthermore, no automatic ballast system is necessary since its lines of Stretches of anchorage prevent any lodging. Finally, as the semi-submersible, the TLP float and its turbine can be docked in the majority of modern port facilities, then towed to the production site.

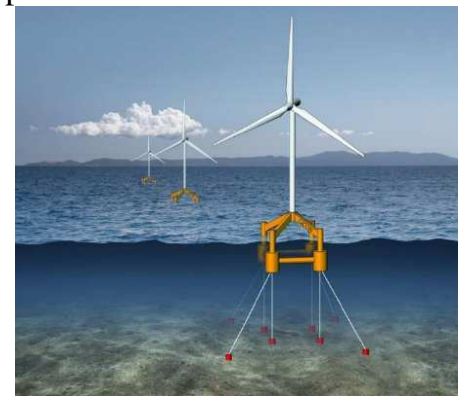

Figure 15. Gicon-SOF by Gicon

The Gicon-SOF project, supported by the company German Gicon, is a research program with a float of the TLP type. The basis of his structure is square, held under the surface of water by 4 lines of vertical moorings, to which are added 4 taut lines oblique to strengthen the stability of the whole. This final design is the result of long basin tests that helped optimize the design of the de- 
monstrator and to minimize the risks. With great flexibility, this float would be installable in depths ranging from 18 to 500 meters. For a $6 \mathrm{MW}$ turbine, its dimensions reach 42 meters on 43 meters high. Its weight is around 1200 tons. Gicon also announces that this method offers support equivalent to a laid offshore wind turbine foundation. This will be verified from spring 2016, when a demonstrator will be installed off the German coast in the Baltic Sea.

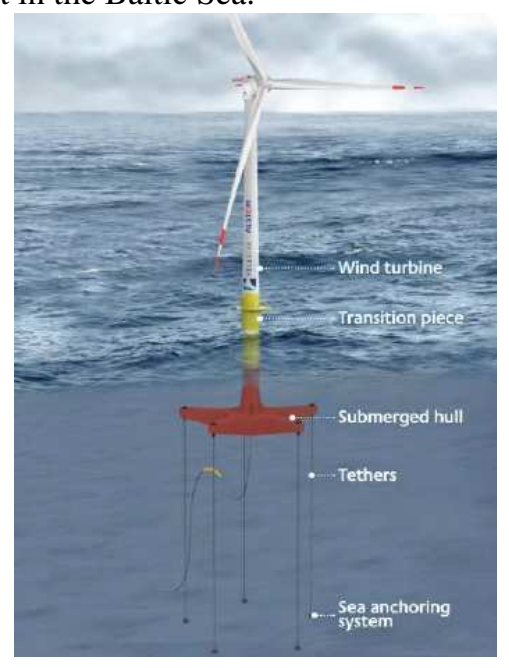

Figure 16. PelaStar by Glosten Associates

Glosten Associates, a Seattle-based engineering firm USA, is behind the PelaStar project, based on a TLP float in the shape of a star with 5 branches. It is retained on the seabed by 5 cables from each of the branches, which are stretched by means of a specially designed for the PelaStar float. In return, his system fastening and the elastic properties of its cables allow to do without on board float winches for readjust the tension. Associated with a turbine with horizontal axis of $6 \mathrm{MW}$ from Alstom, this demonstrator was to be installed off Cornwall in the UK but Glosten

Associates recently lost this contract. They are now looking for a new test site for a installation in 2018.

\subsection{MULTI-TURBINE PLATFORM AND HYBRID PLATFORM}

There are other types of platforms devised by some engineering firms, in Europe and elsewhere. Japan. For the moment, these platforms remain avenues for reflection, none being planned for the test at real size in the world.

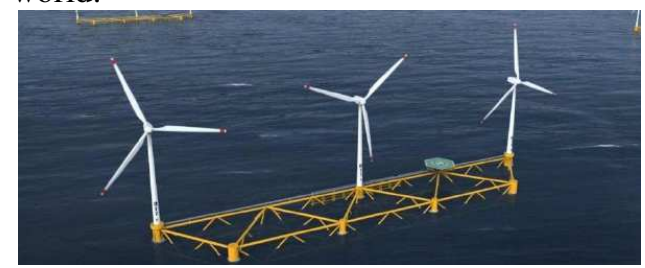

Figure 17. Hexicon by Hexicon (Sweded)

First, multiturbine platforms are like their name indicates it, composed only of a float for several turbines. The goal is to maximize the profitability of the float creating a structure developing a big power. Of the semi-submersible type, imagined floats welcome up to 3 wind turbines. The problem of anchoring can, however, arise, it will indeed have to be extremely robust to remember all. An efficient automatic ballast system is also to be expected. These last two criteria increase nevertheless the price of the concept.

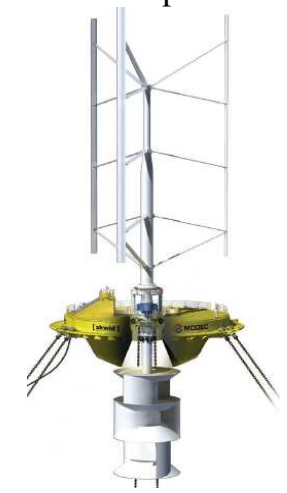

Figure 18. SKWID by Modec (Japan)

Finally, the hybrid platform is another project that allows the cost of float. Composed of a vertical axis wind turbine outside and a tidal turbine under the surface of water, this process would ensure the continuity of 
energy production. Indeed, when the wind is not enough to produce, the tidal turbine would take over and vice versa. We can also imagine the simultaneous operation of both turbines. The stability of the whole is obtained thanks to the weight of the tidal turbine which lowers the center of gravity of the platform, like a SPAR float.

\section{ANCHORAGE LINES}

The different mooring technologies currently in use for oil rigs apply perfectly to floating offshore wind turbines. This is how the materials used will be steel or synthetic fiber, in the form of cable or chains, in catenary configuration, taut or semi-stretched lines. Three wetting configurations are distinguished for a float. Tight anchor lines for TLP floats, catenary damping for SPAR and semi-submersible floats and finally, less common, semi-stretched wetting, adapted to a semi-submersible float.

\subsection{TENSIONED ANCHORING LINES}

TLP float needs tethered anchor lines to ensure its maintenance. For this configuration, the two materials used are steel wire and line in synthetic fibers.

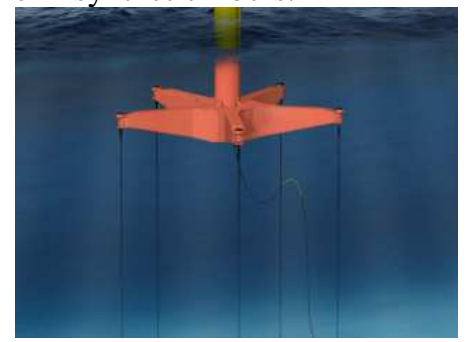

Fig.19. Tensioned anchoring lines

The main advantage of steel is its price. The second is the low elasticity of the cable. This helps to keep a significant voltage continually in order to keep the float stationary. However the weight of cable is nonnegligible, and its rigidity complicates all the more its manipulation. This is why we often associate a synthetic fiber section with the end of the steel cable.
For its part, the benefits of synthetic fiber push most manufacturers to opt for this material. First of all, its weight is much less than steel. Some fibers even have a density lower than water and then participate in the buoyancy of the whole. Moreover, she is easily manipulated which makes installation and power-up faster. She resists also better in time to the marine environment. However she will have a stronger elastic deformation as steel, which can affect the stability of the float. The fiber used is the more often the polyester which has a very high resistance to break, even wet. As for example, for a single diameter of $48 \mathrm{~mm}$ its breaking load will be more than 80 tons.

Perfectly vertical in the TLP configuration, the mooring lines have a very small footprint on the ground because only the anchors rest on the seabed. This reduces their impact on the environment.

On the other hand, the forces that apply on the anchors are higher than for the anchorage catenary and the semi-stretched. This results in the need for anchor lines with a load superior breakage and more expensive. However, it turns out that the price of mooring lines tension is half that of catenary mooring. This is achieved thanks to the length of the lines at equal depth, on average 700 meters for the catenary, against 80 meters for the tense.

\subsection{CATENARY ANCHORING LINES}

Catenary mooring is the most common among existing projects. It is suitable for floats semi-submersible than SPAR floats. In this configuration, at least one-third of the line rests on the bottom. It's the weight of the lines and their curved shape that will, in most cases, limit the movements of the float. In the case of difficult weather conditions, where only the weight of the lines would not be enough to prevent any movement, the latter transmit horizontally pulling forces to the anchors. 


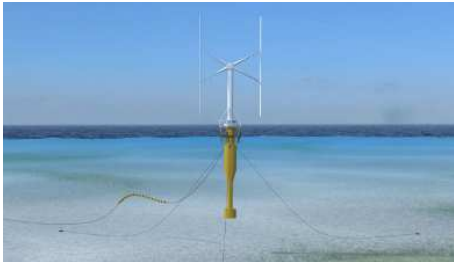

Fig.20. Catenary anchoring lines

The material used for all projects existing is steel, in the form of cables or chains. Indeed, the anchorage catenary does not leave any alternative at the choice of the material, the synthetic fiber being far too light to ensure a good catenary mooring. Moreover, since the length of the line is climbing considerably its price, only steel helps to stay profitable.

The catenary wetting has a strong footprint. Lines remaining largely stretched on the seabed, it is continually disturbed. The tension on the wetting lines is reduced compared to the wetting with taut lines. So, he it is not necessary to have a line breaking load as important as for the configuration with taut lines.

\subsection{SEMI-TENSIONED ANCHORING LINES}

Only the Nezzy SCD project from German Aerodyn Engineering chose the semistretched wetting. It is neither more nor less than a combination of catenary mooring and tension. Indeed, the constraints on the lines and the anchors are less important than for the tension but higher than for the catenary. Similarly, the impact of the footprint remains important compared to the TLP but less than the catenary.

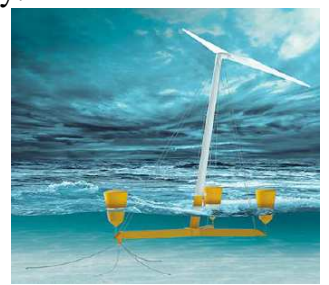

Figure 21. Nezzy SCD Project by Aerodyn Engineering
The materials used will be either fiber synthetic, the steel cable. For this project a little particular, all the lines are connected in a single point of the float, equipped with a pivoting axis. This will give the float the opportunity to evolve around this point, in order to place the wind turbine in the axis of the swell and thus limit the constraints.

\section{ANCHORINGS}

The anchoring is very varied on all floating wind projects. It obviously depends on choice of the configuration of the anchor lines, but also the quality of the seabed and the tension applied on the anchors. This technology is also well mastered by industrialists, with their experience in the exploitation of offshore oil and gas fields.

\subsection{ANCHOR DREDGE}

This type of anchor is particularly suitable for mooring with catenary lines. Its shape is designed to withstand horizontal pull, its holding capacity is then obtained by the resistance of the ground facing the advanced from the flat part of the anchor.

Its installation is relatively easy with the help of AHTS type tug vessels, it will penetrate several meters in the ground, and sometimes up to twenty meters in the most soft soils.

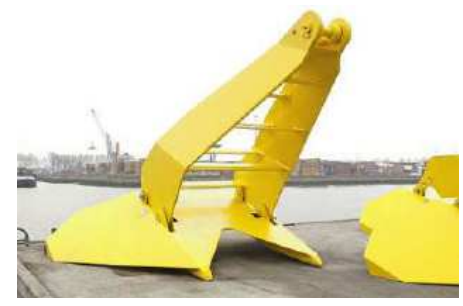

Figure 22. Anchor dredge

It is recommended for soils consisting of agglomerated sediments. It will be necessary to ensure that they do not do not be too hard to allow the anchor to penetrate. During the dismantling of the wind turbine, the anchor to be dredged can be recovered. Afterwards, it will be reused or recycled according to the state of wear. 


\subsection{EMBEDED PILE}

The pile, also called pile, can be applied to all types of mooring. It is made to withstand loads of all directions, horizontal for the catenary, at 45 degrees for the semistraight and vertical for the tense anchorage.

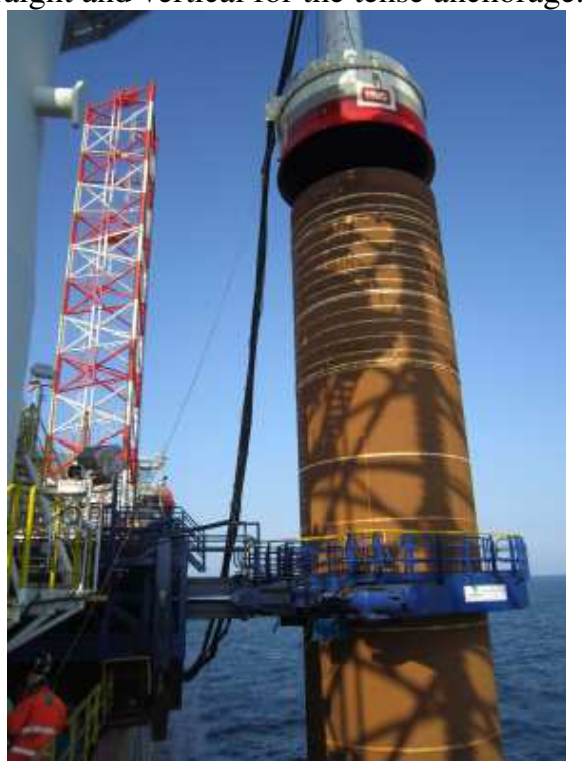

Figure 23. Pressing a pile by hydraulic pressure

Its installation involves driving a stake into the ground marine, by vibration, by hydraulic pressure or by drilling. There is also the possibility of casting directly into the soil the concrete constituting the pile. As for example, for the foundations of an offshore wind turbine placed, the depression of the pile is done on a length ranging from 20 to 130 meters, depending on the properties of the soil on which she is.

The battery is suitable for a wide range of different soils and the various installation processes give the possibility of adapt to the hardness of the soil if needed.

For the dismantling of the wind turbine, it will be very difficult and sometimes impossible to recover the battery. Most of the time this type of foundation is left in the sea floor.

\subsection{SUCTION PILE}

As the battery is depressed, the suction battery is suitable for all types of mooring, with push-ups in different directions, from the vertical to the horizontal.

The suction pile is easier and faster to install the battery down, especially when the depths increase. Its structure takes the form of a bell that sinks into the sea floor. We then apply a negative pressure under the bell which will have the effect of locking down his depression. The mooring line is attached to the side of the pile, at the point where the optimum fixation.

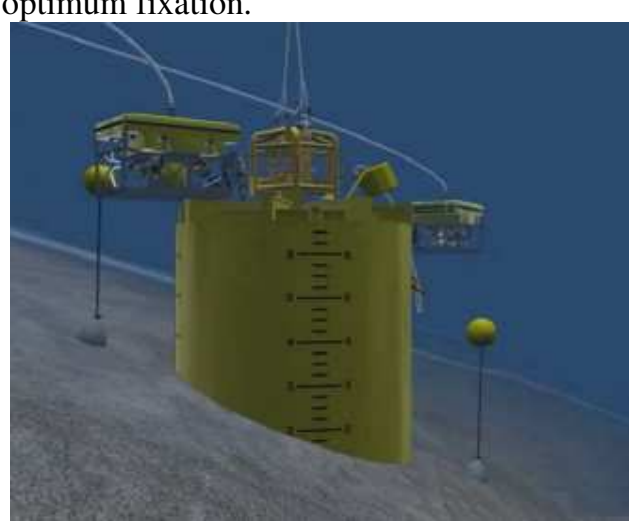

Figure 24. Suction pile.

It works very well for soils composed of soft clays and more generally the soils of which penetration is easy, but is not applicable to hard floors. The suction cell can not be installed on loose sandy soils, where it is not possible to obtain pressure negative enough. It has the advantage of being easily recoverable during the dismantling of the wind turbine. It is enough to increase the pressure under the bell until the necessary positive pressure.

\subsection{GRAVITY ANCHOR}

The gravity anchor is the simplest anchoring system to conceive. It retains the float only thanks to its heavy mass that remains on the bottom. The average weight an anchor being 650 tons for current projects. It is best suited for anchoring with tight lines but can be found sometimes with a catenary 
mooring. Its installation is very simple, since it is enough to ask without necessarily pushing it.

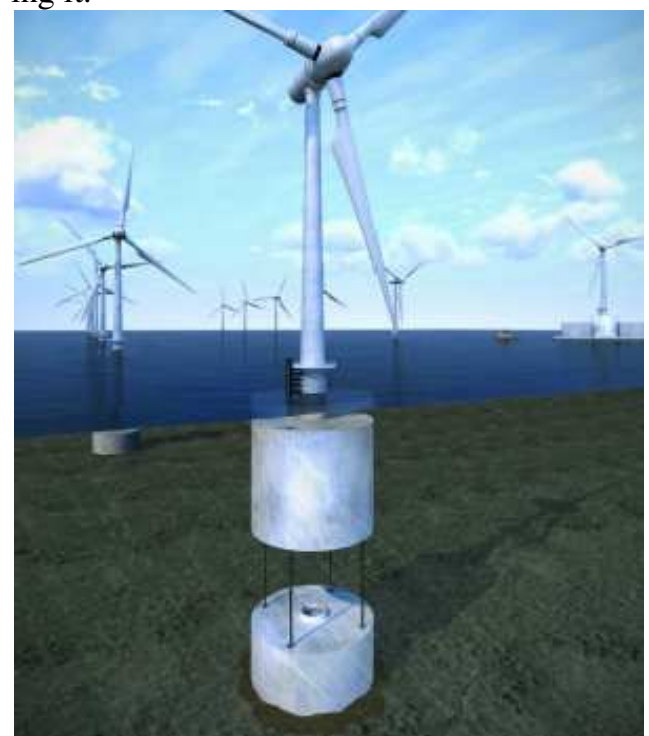

Figure 25. Gravity anchor.

The gravity anchor is intended for hard floors. Indeed, on soft ground anchors could sink unequally, which would destabilize the whole. She stays also incompatible with rocky bottoms, unless a background preparation beforehand to smooth it out. This obviously increases the cost of installation.

The gravity anchor will rarely be recovered during the dismantling of the wind turbine. Its weight and size make the task very difficult. In addition, the anchor acts as an artificial reef that is often judged better not to move.

\section{CONCLUDING REMARKS}

Offshore floating wind is emerging as a promising technology. The many benefits it offers to bet on its rapid development in the world. Indeed, experts estimate that a potential of $15 \mathrm{GW}$ offshore wind and $6 \mathrm{GW}$ floating wind is exploitable by 2030 off the French coast. In addition, industrialists of the sector are among the most creative in the world, presenting innovative projects floating wind. But this hard-won advance is about to fade with the recent announcement of Statoil that plans to deploy a pilot fleet of 5 wind turbines in 2017.

Despite its advantages, floating offshore wind turbines remain far from supplanting all other technologies. It will only succeed if it becomes competitive, ie by reducing its cost of production until it rivals the best in the field. Nuclear power generation currently costs $€ 50 / \mathrm{MWh}$ and that of onshore wind between $€ 70$ and $100 €$ of the MWh. The offshore wind turbine installed is $180 € /$ MWh when floating offshore wind is still between 250 and $350 €$ per MWh. All the challenge of floating now is to approach 100 $€ \mathrm{MWh}$, but the industrialists are confident.

Moreover, the cost of production is not the only criterion to be taken into account. If we are interested in "Global cost" of technologies, floating offshore wind is in fact very well placed. Indeed, the "Overall cost" includes the cost of production, but also the cost of production, maintenance, dismantling and finally recycling of materials. As seen previously in this study, the environmental impact of a floating offshore wind farm after its dismantling is extremely weak, nothing is left on the seabed. In addition, a wind turbine is $98 \%$ recyclable because only the blades can not be recycled because of the composite materials used. In comparison, the foundations of an offshore wind farm posed cause irreversible damage to their environment, since they can not be removed. The case of nuclear power is even more obvious, the dismantling and recycling of materials and fuel from a nuclear power plant detonates its "overall cost".

With floating offshore wind turbines, industrialists are not embarking on the unknown. The principle of the offshore wind turbine has been mastered since the 70 s and that of floats with their anchorages since the 80 s, thanks to offshore oil and gas.

For all these reasons, floating offshore wind energy offers manufacturers a reduced financial risk and renewed confidence to innovate, develop and undertake. 
Let us bet that the profitability of this new generation wind turbine will be reached quickly, which will ultimately be the only guarantee of its success in the energy market.

\section{REFERENCES}

[1]. Bak, C. et al., "Light rotor: The 10-MW reference wind turbine", Proc. of EWEA European Wind Energy Conference, 2012.

[2]. Bayati, I. et al., "Scale model technology for floating offshore wind turbines", IET Renewable Power Generation (Vol.11, Issue.9), 2017.

[3]. Bracq, G., "L'eolien offshore flottant", In IFM Méditerranée, Revue Maritime, November, 2016.

[4]. Bulder, B. et al., "Floating OffShore Wind Turbines for Shallow waters", European Wind Energy Conference, Madrid, 2003.

[5]. Fontana, C.M. et al., "Multiline anchor force dynamics in floating offshore wind turbines", Wind Energy, Volume21, Issue11, pag. 1177-1190, November, 2018.

[6]. Hendriks, H.B. et al., "DOWEC Concept Study: Evaluation of Wind Turbine Concepts for Large Scale Off-Shore application", In Proceedings of the European Seminar Offshore Wind Energy in Mediteranean and other European Seas, pages 211-219, April 2000.

[7]. IRENA, "Innovation Outlook: Off shore Wind", International Renewable Energy Agency, Abu Dhabi, 2016.

[8]. James, R., Costa Ros, M., "Floating Offshore Wind: Market and Technology Review “, () The Carbon Trust, Prepared for the Scottish Government and Published in the UK, June, 2015.

[9]. Jonkman, J. et al., "Definition of a 5-MW reference wind turbine for off-shore system development", National Renewable Energy, 2009.

[10]. Roddier, D. et al., "Windfloat: A floating foundation for offshore wind turbines", Journal of Renewable and Sustainable Energy, 2010.

[11]. Snijders, E.J.B., “Concept design floating wind turbine", report P 10499-3940, MSC, September 2002.

[12]. Stewart, G., Muskulus, M., "A review and comparison of floating offshore wind turbine model experiments", In Energy Procedia 94 ( 2016 ) 227 - 231, 13th Deep Sea Offshore Wind R\&D Conference, EERA DeepWind, Trondheim, Norway, 2016.

Paper received on December $15^{\text {th }}$, 2018 